LA W RENCE LIVERMORE NATIONAL LABORATORY

Flow Analysis Baseline Heated Flow Turbulence Model Comparison

S. B. Sutton

January 31, 2011 
This document was prepared as an account of work sponsored by an agency of the United States government. Neither the United States government nor Lawrence Livermore National Security, LLC, nor any of their employees makes any warranty, expressed or implied, or assumes any legal liability or responsibility for the accuracy, completeness, or usefulness of any information, apparatus, product, or process disclosed, or represents that its use would not infringe privately owned rights. Reference herein to any specific commercial product, process, or service by trade name, trademark, manufacturer, or otherwise does not necessarily constitute or imply its endorsement, recommendation, or favoring by the United States government or Lawrence Livermore National Security, LLC. The views and opinions of authors expressed herein do not necessarily state or reflect those of the United States government or Lawrence Livermore National Security, LLC, and shall not be used for advertising or product endorsement purposes.

This work performed under the auspices of the U.S. Department of Energy by Lawrence Livermore National Laboratory under Contract DE-AC52-07NA27344. 


\section{Flow Analysis}

\section{Baseline Heated Flow}

\section{Turbulence Model Comparison}

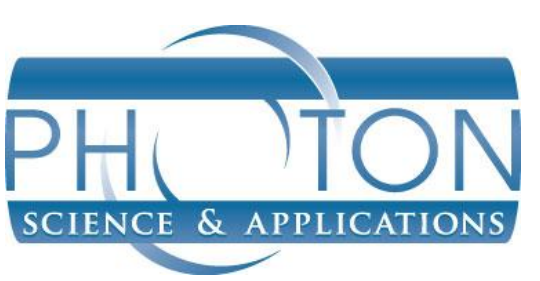

Steven Sutton

January 18, 2011

LLNL-TR-468217 


\section{Outline ...}

- Calculations were performed using four turbulence models

$\circ$ Reynolds-averaged Navier-Stokes (RANS)

- Standard Spalart-Allmaraz

- Standard k- $\varepsilon$ model

$\circ$ Detached Eddy Simulation (DES)

- Spalart-Allmaraz Detached Eddy

○ Large Eddy Simulation (LES)

- Calculations were run in two stages: steady-state initialization followed by the transient solution

- The Standard Spalart-Allmaraz steady-state solution was used for the DES and LES transient simulations 


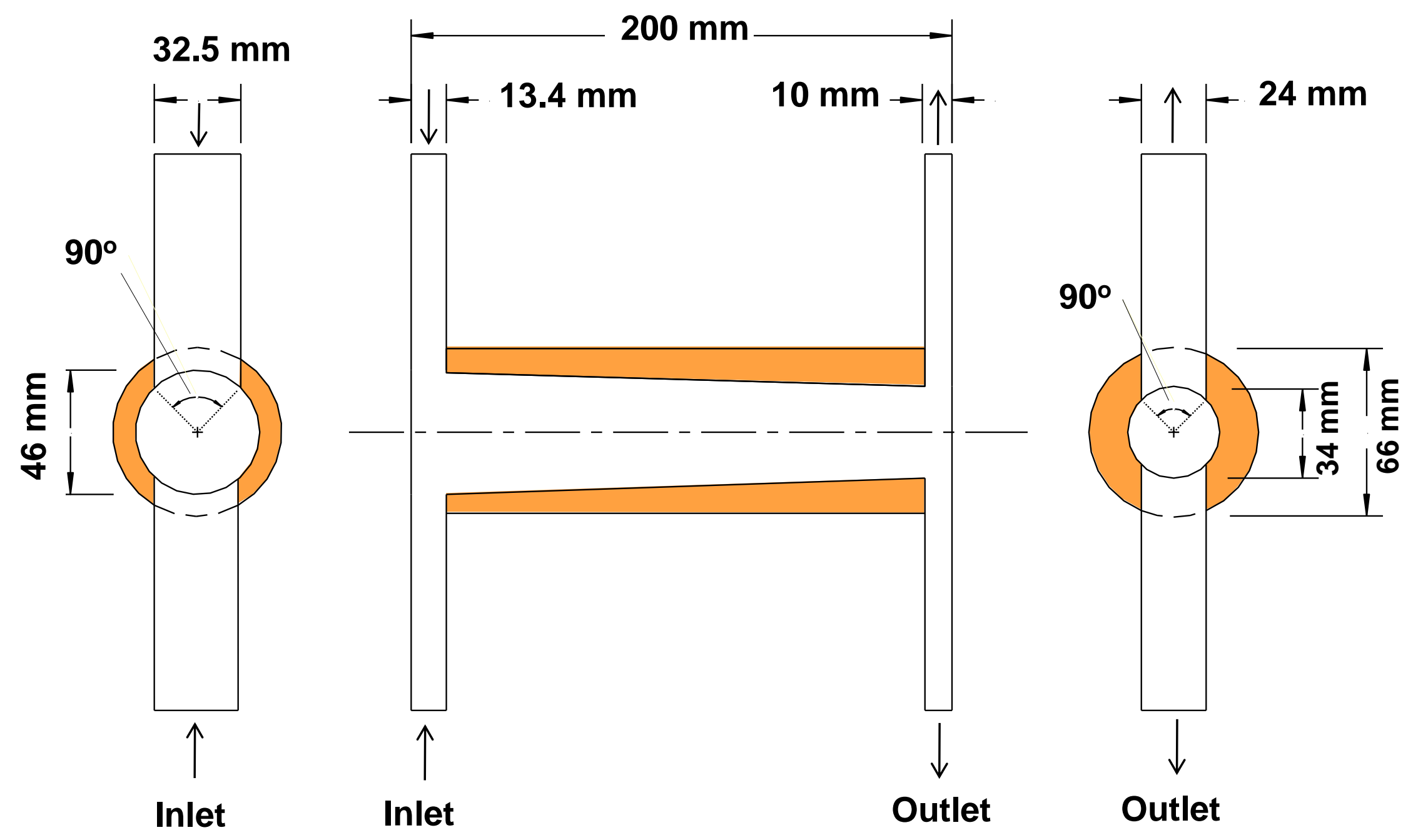




\section{Key features of the model}

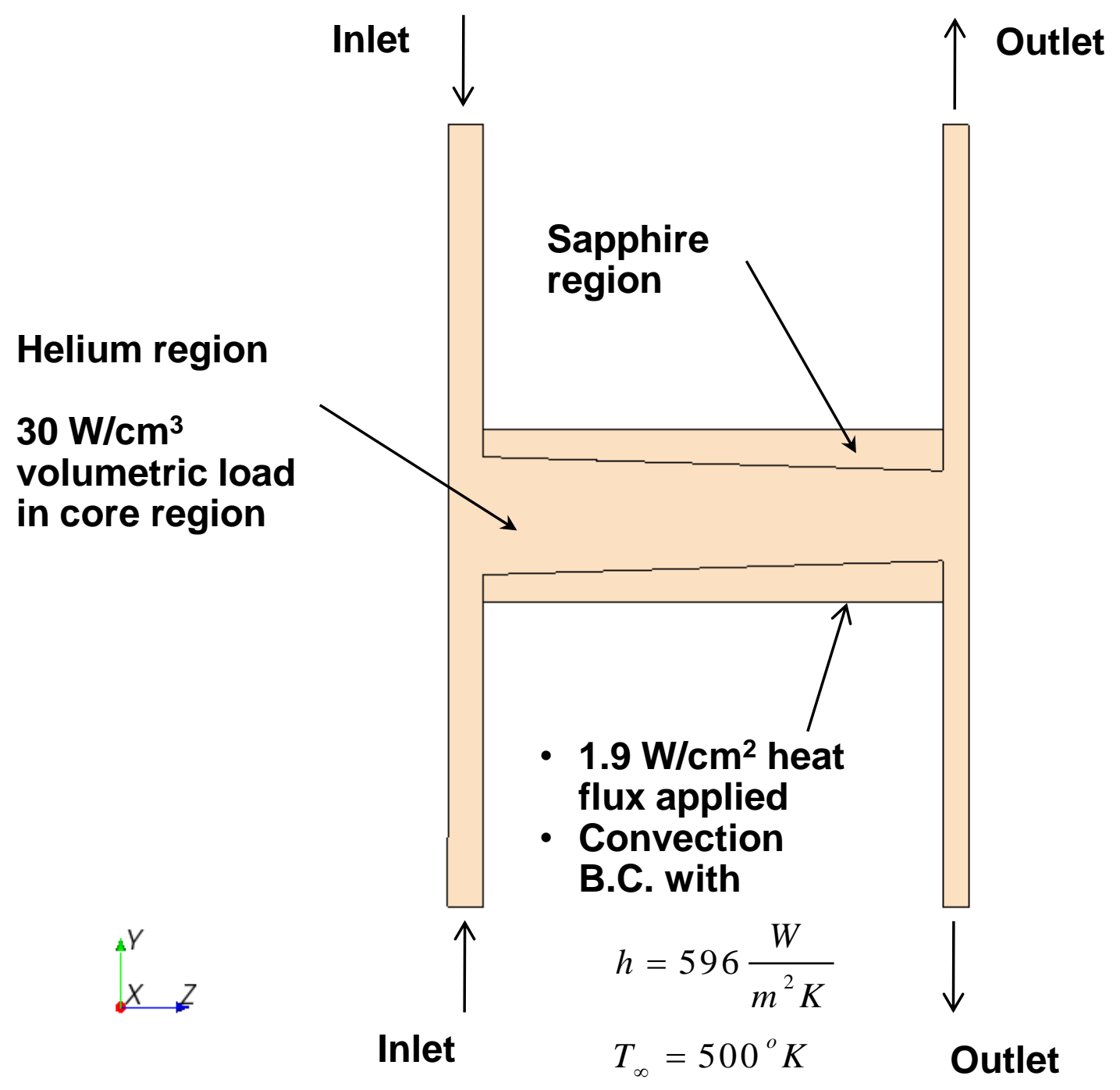


- Helium region:

- 3,481,600 cells

- 4864 elements in the truncated cone cross-section

- 550 element slices in the core flow direction

- Sapphire region:

- 199,680 cells

- 170 element slices in the core flow direction

- A coarser mesh is allowed in the Sapphire region because the Sapphire thermal conductivity is much greater than the Helium thermal conductivity 
Helium region mesh plots

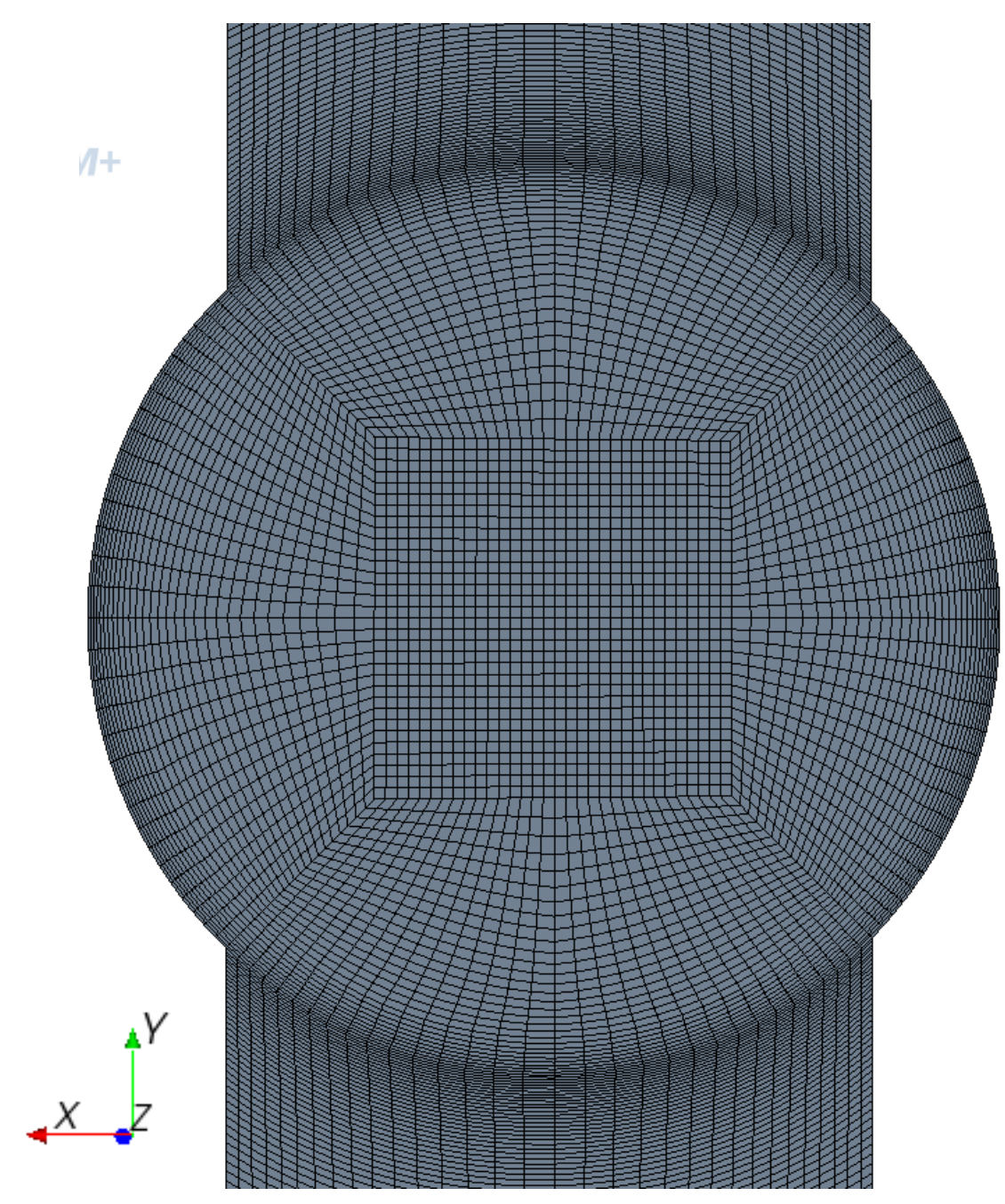

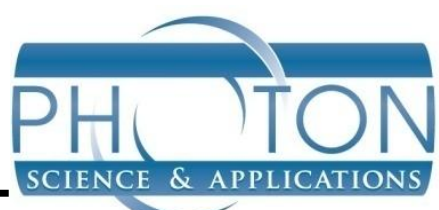

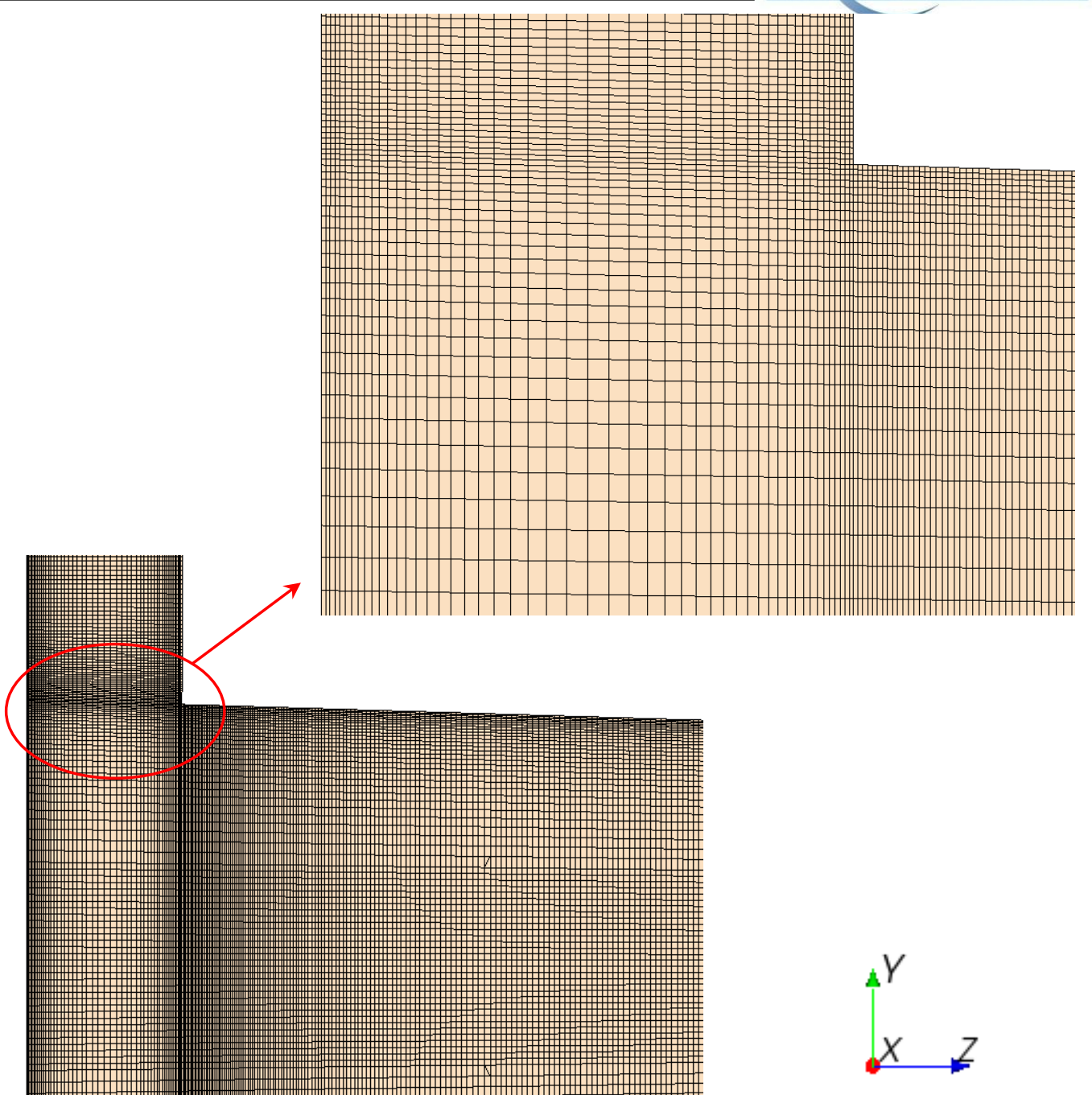


Velocity, temperature and density information was saved at 33 discrete points for time-history plots
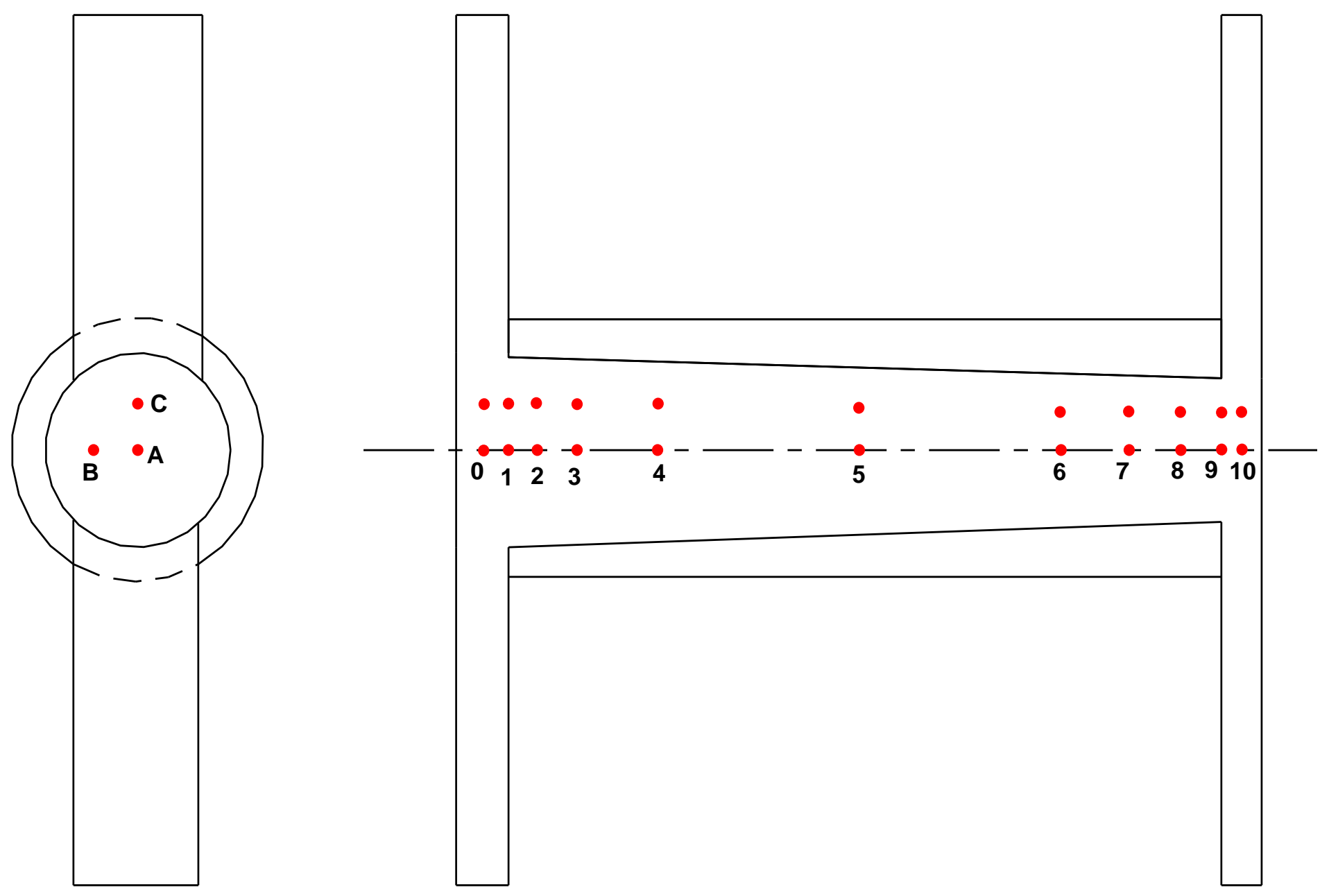


\section{Standard Spalart-Allmaraz Turbulence Model - Velocity magnitude}
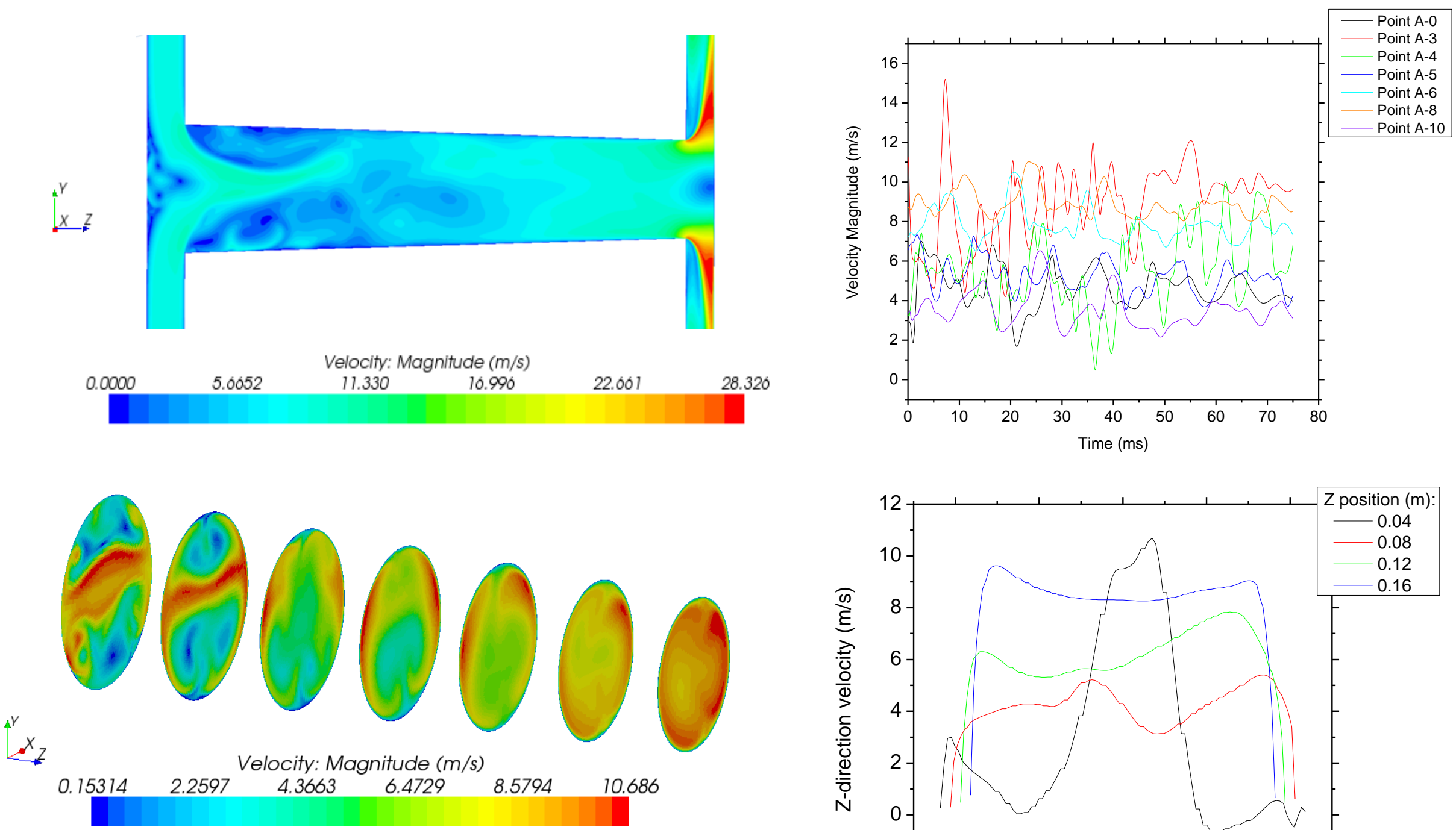

(Case 38.1b)

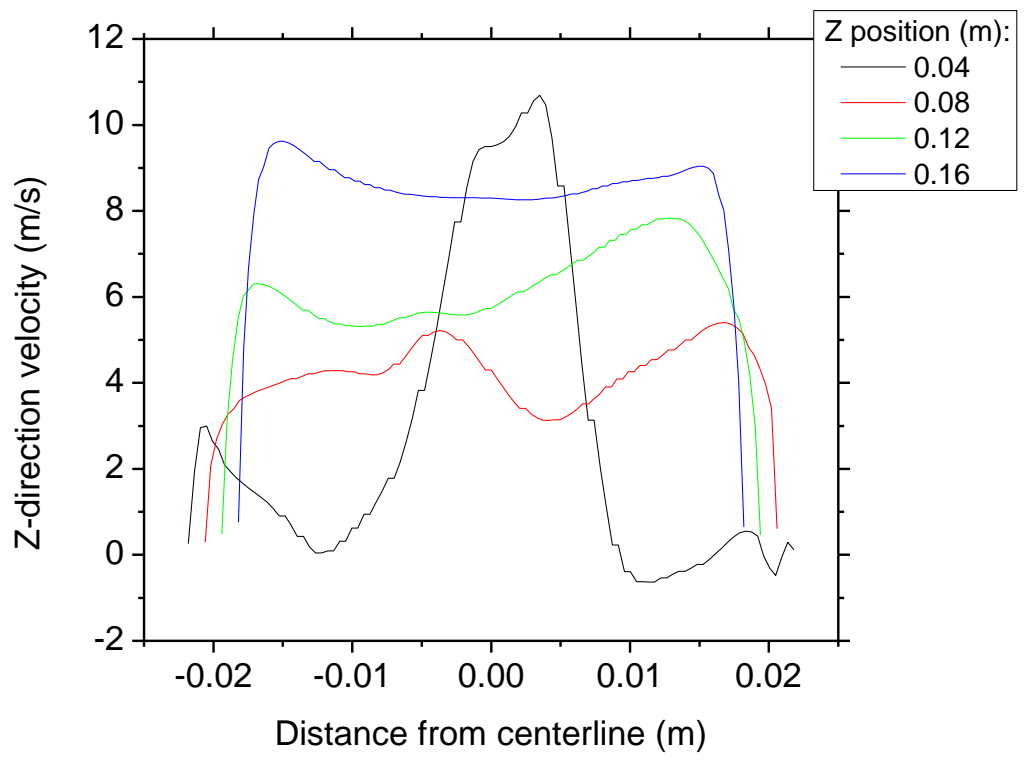




\section{Standard Spalart-Allmaraz Turbulence Model}

- Temperature
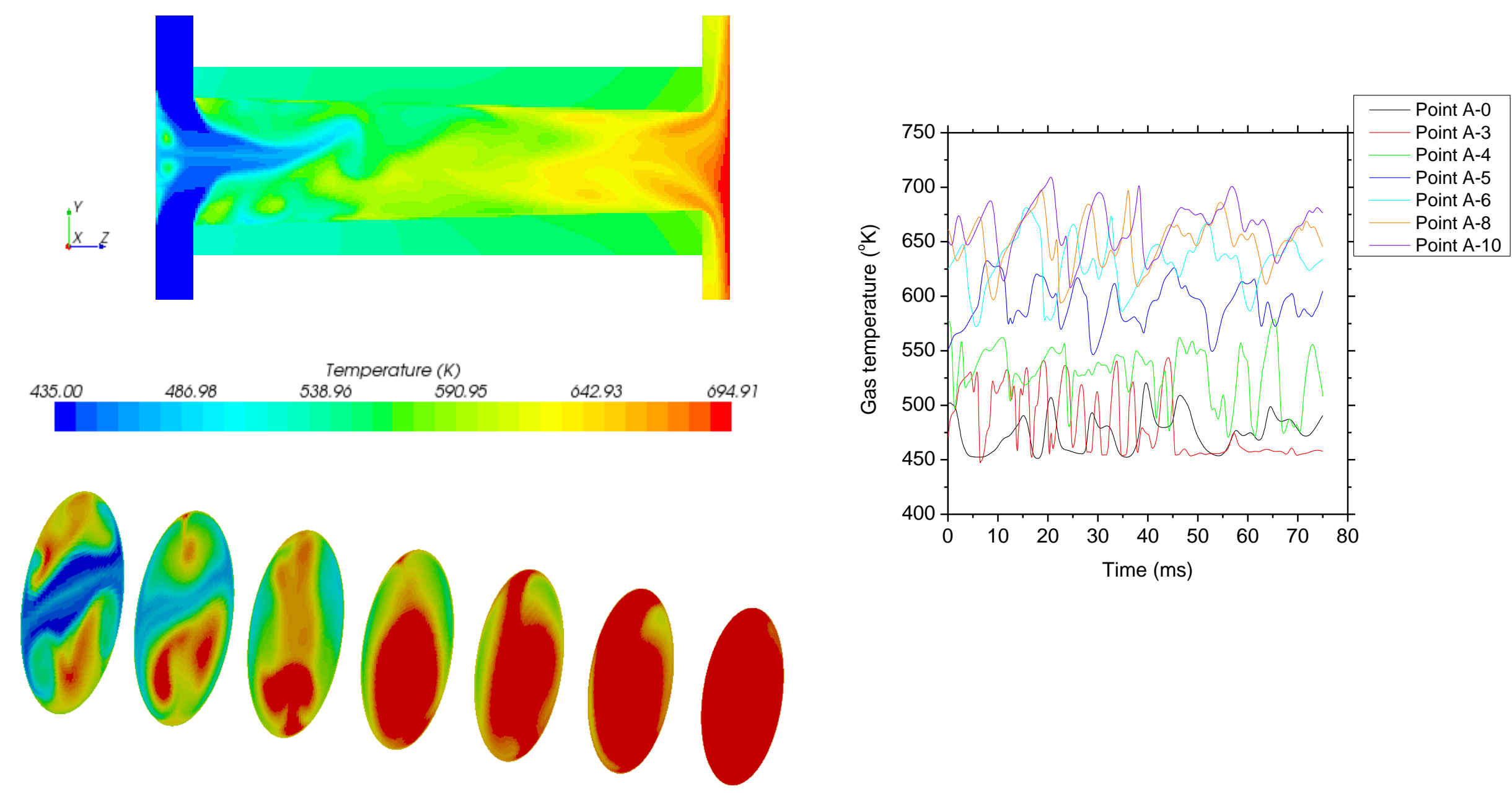

Temperature (K)

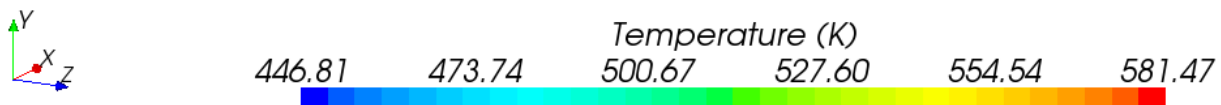

(Case 38.1b) 


\section{Standard Spalart-Allmaraz Turbulence Model}

- Density
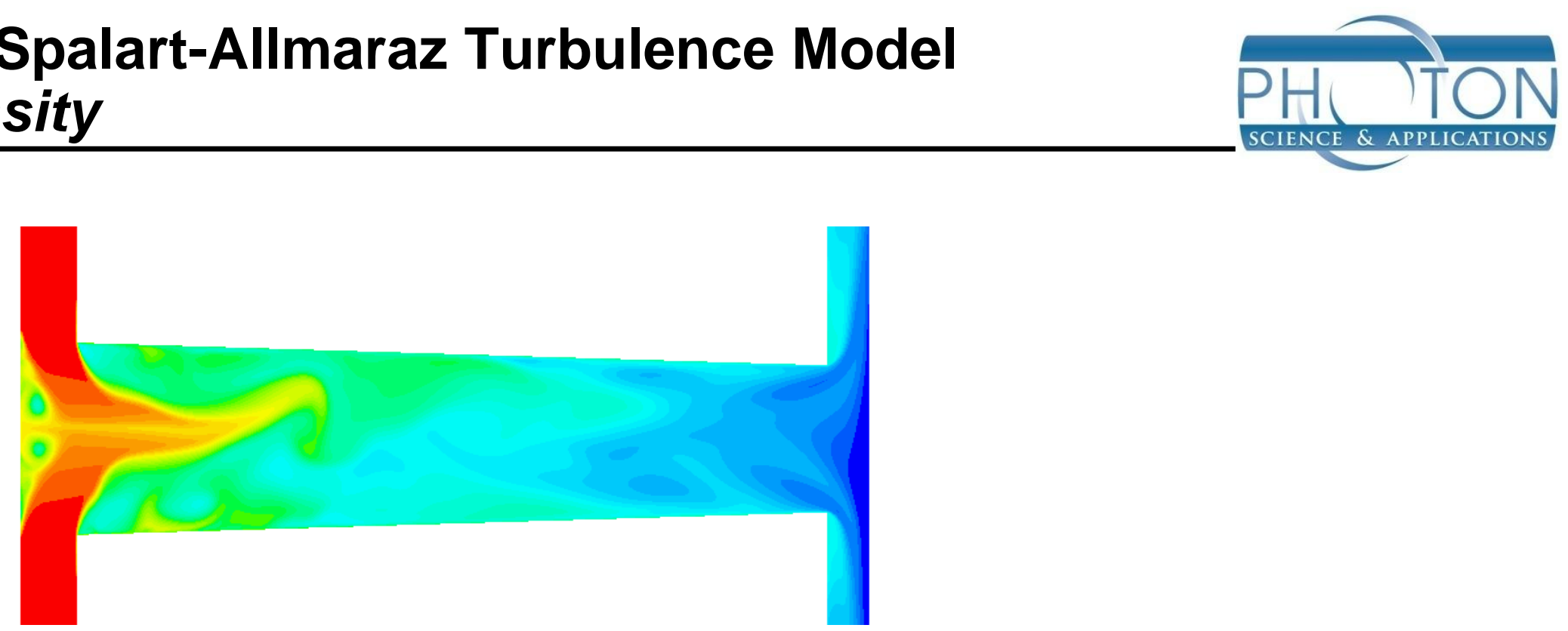

$Y$
$X \quad Z$
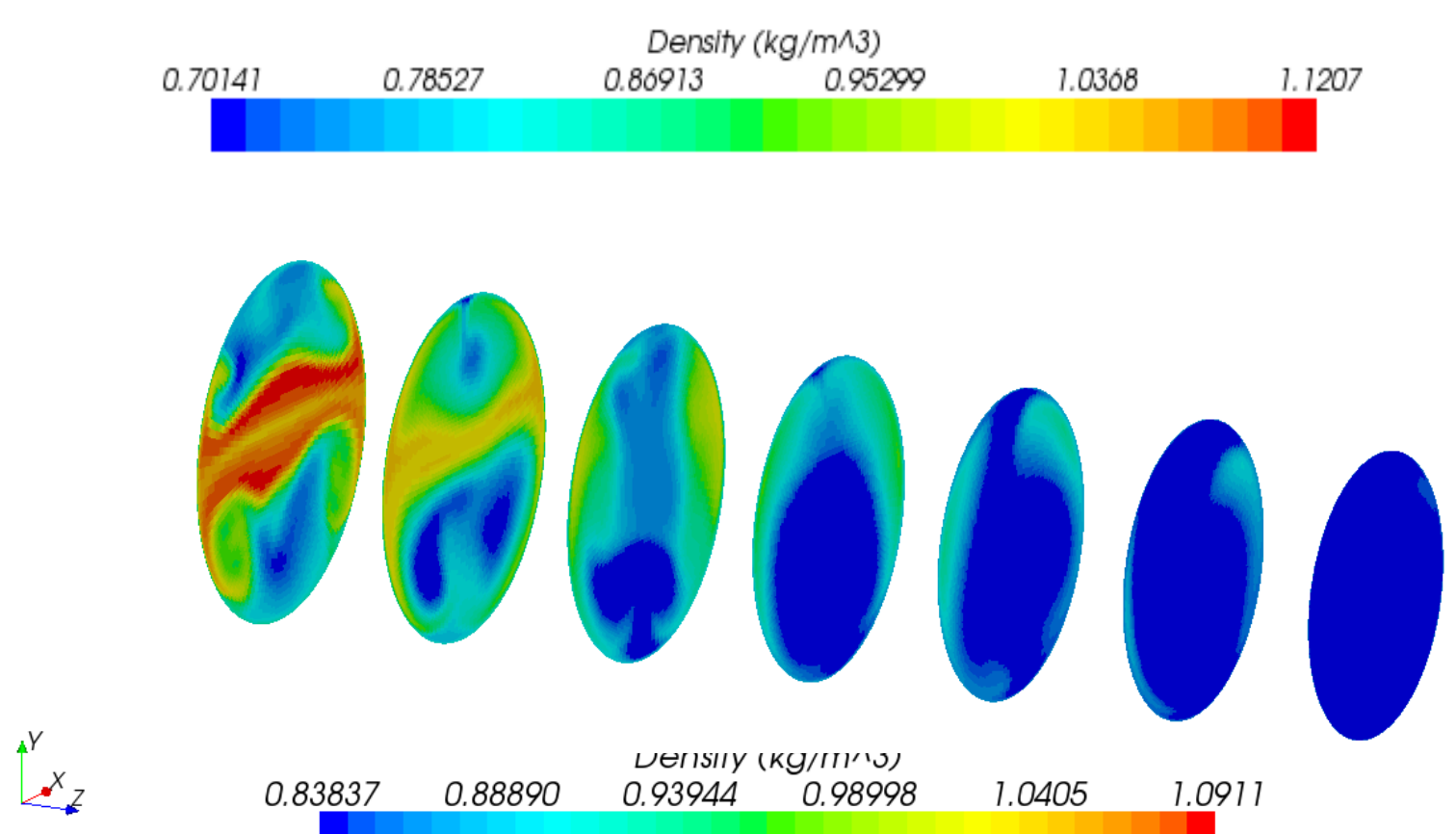

$$
0.83837
$$

0.88890

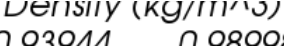




\section{Standard Spalart-Allmaraz Turbulence Model}

- Turbulent Viscosity Ratio
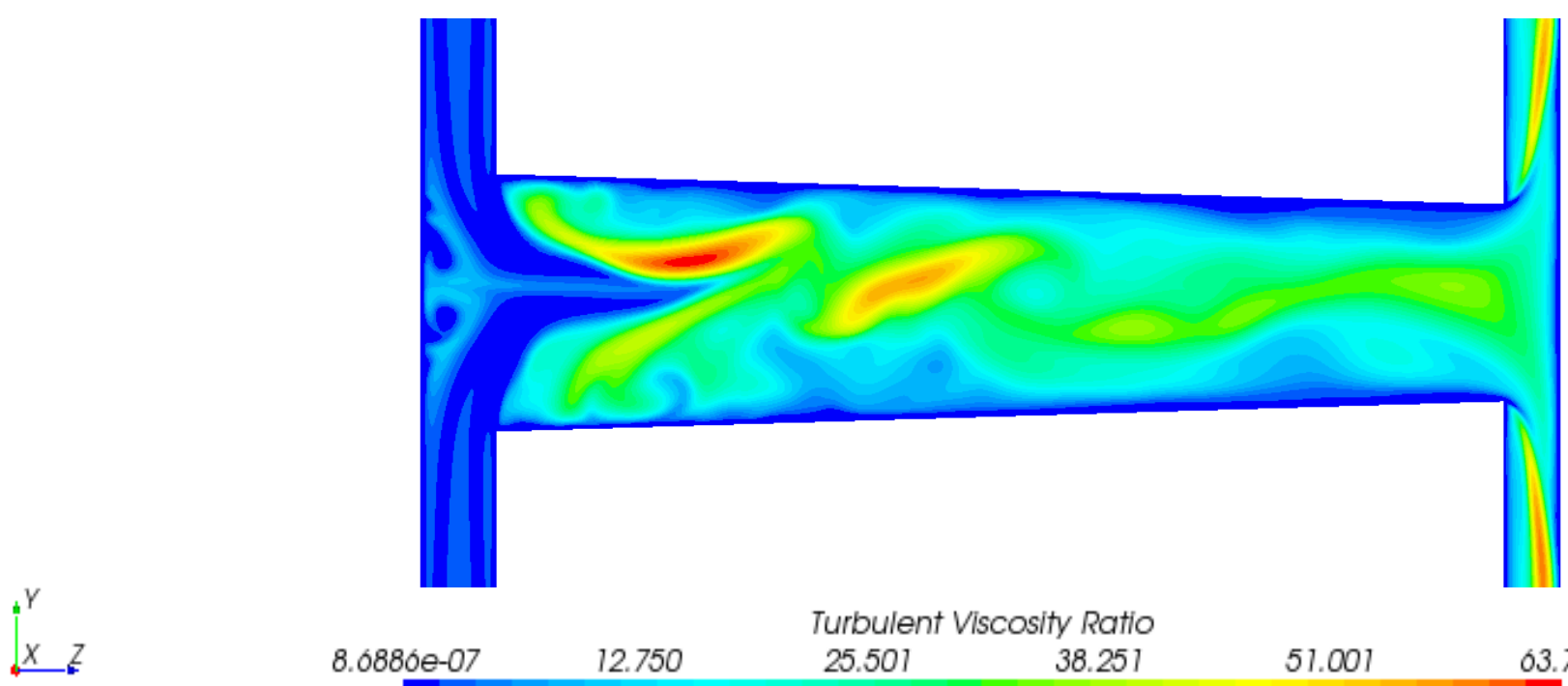

$8.68800-07$

12.750

25.501

38.251

51.001

03.752

(Case 38.1b) 


\section{Spalart-Allmaraz Detached Eddy Turbulence Model \\ - Velocity Magnitude}
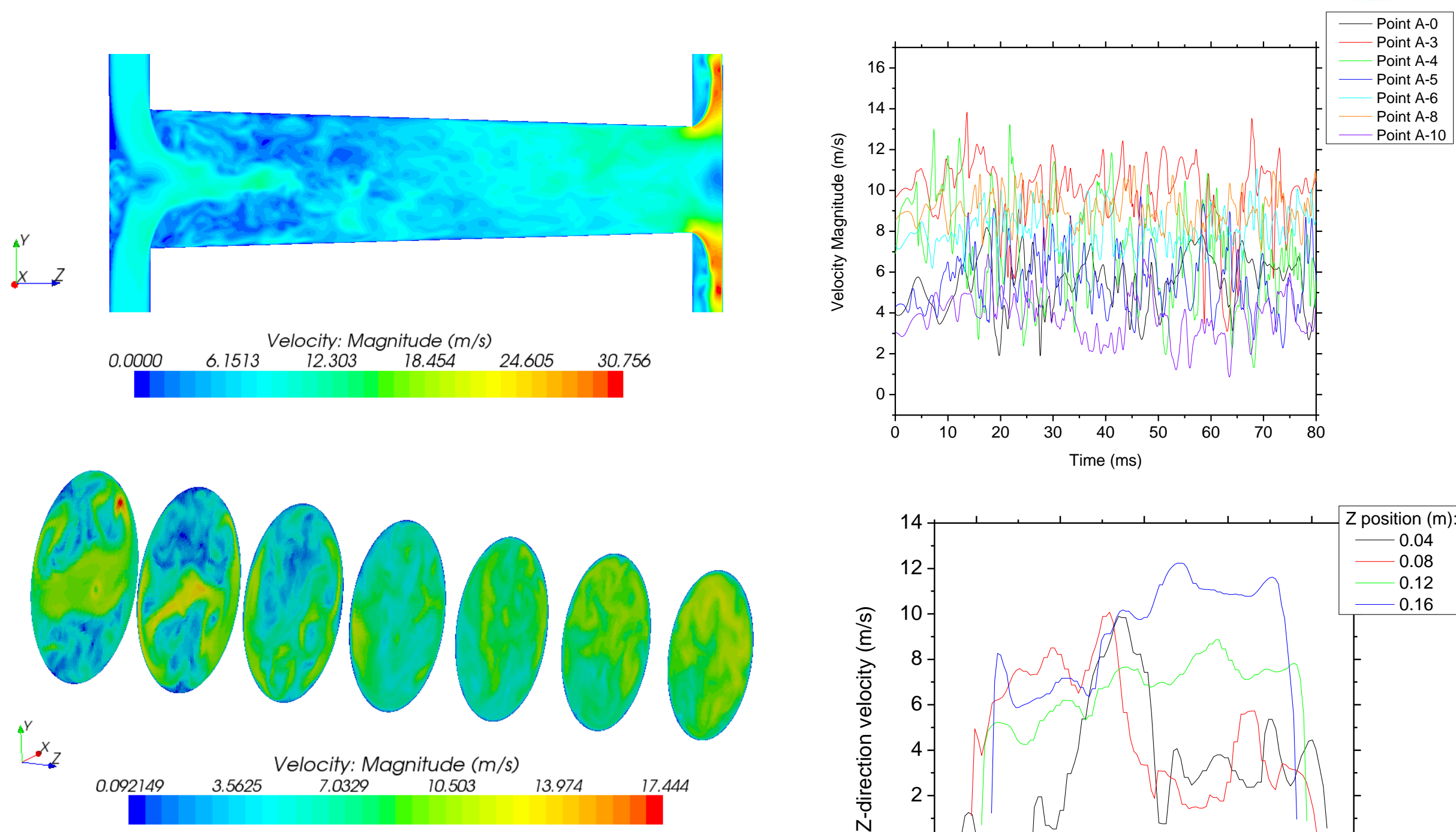

(Case 38.2b)

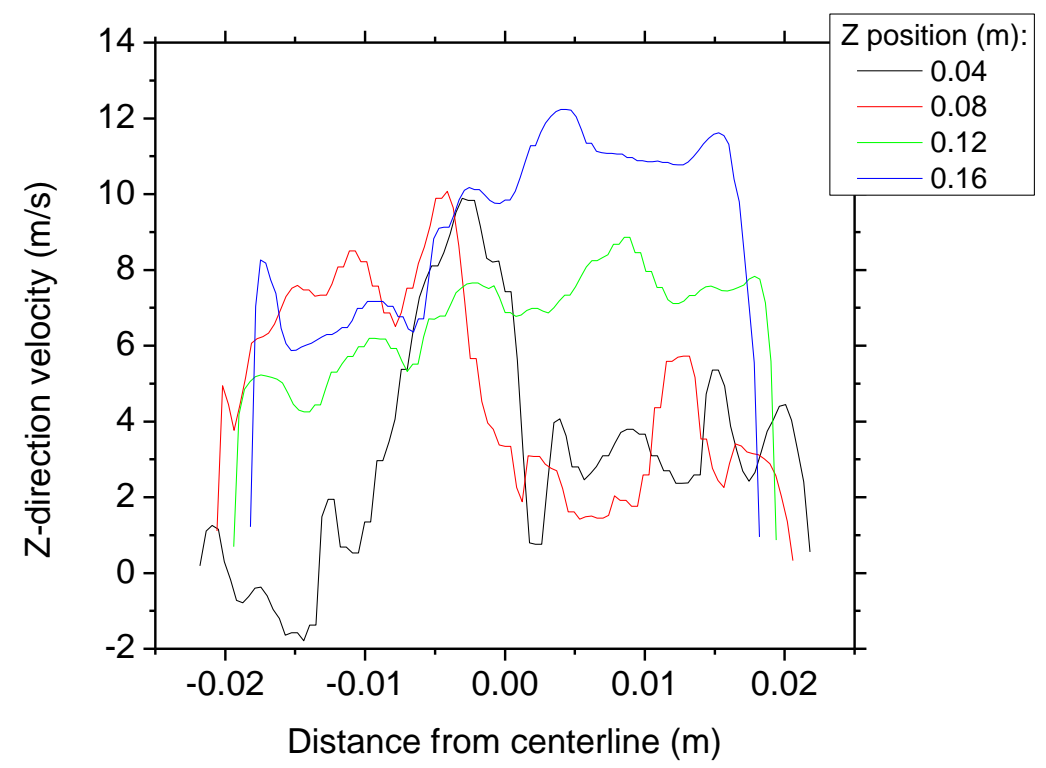




\section{Spalart-Allmaraz Detached Eddy Turbulence Model}

- Temperature

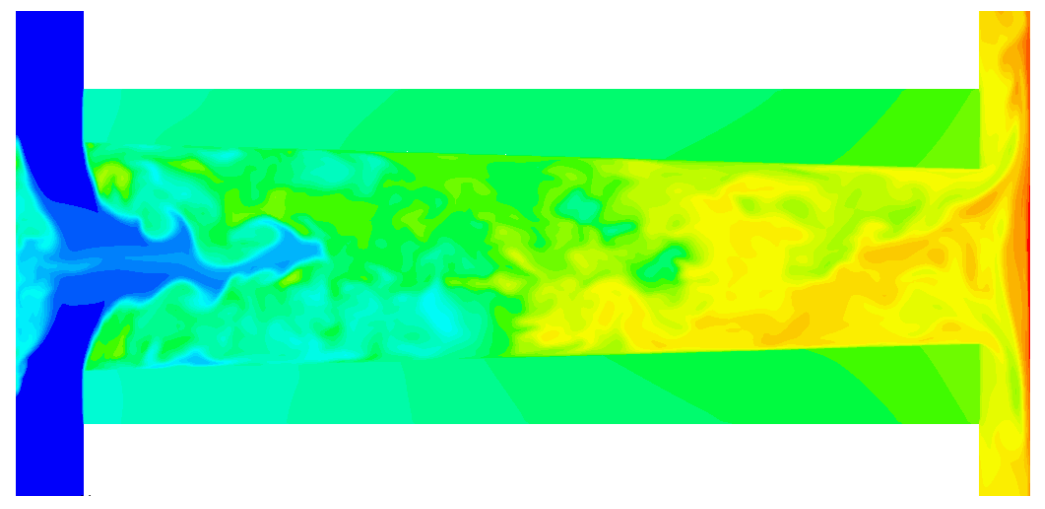

$\int_{X}^{Y} \quad Z$
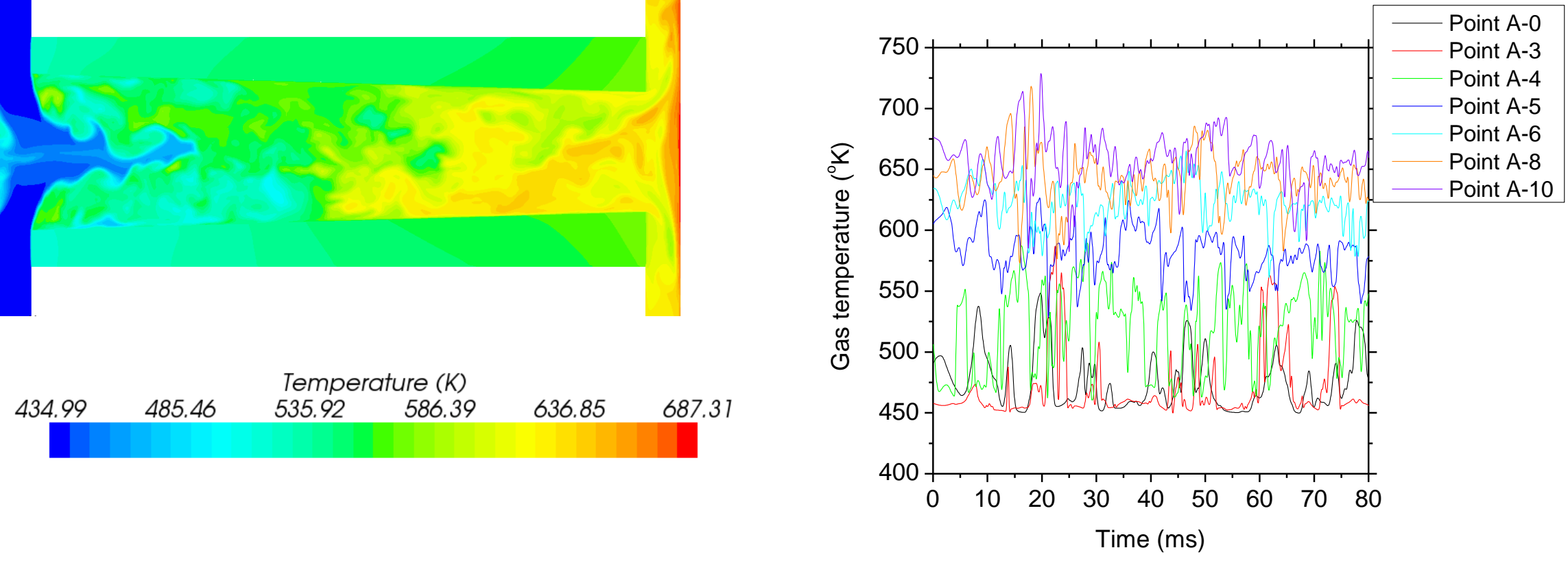

$2^{x} x_{2}$
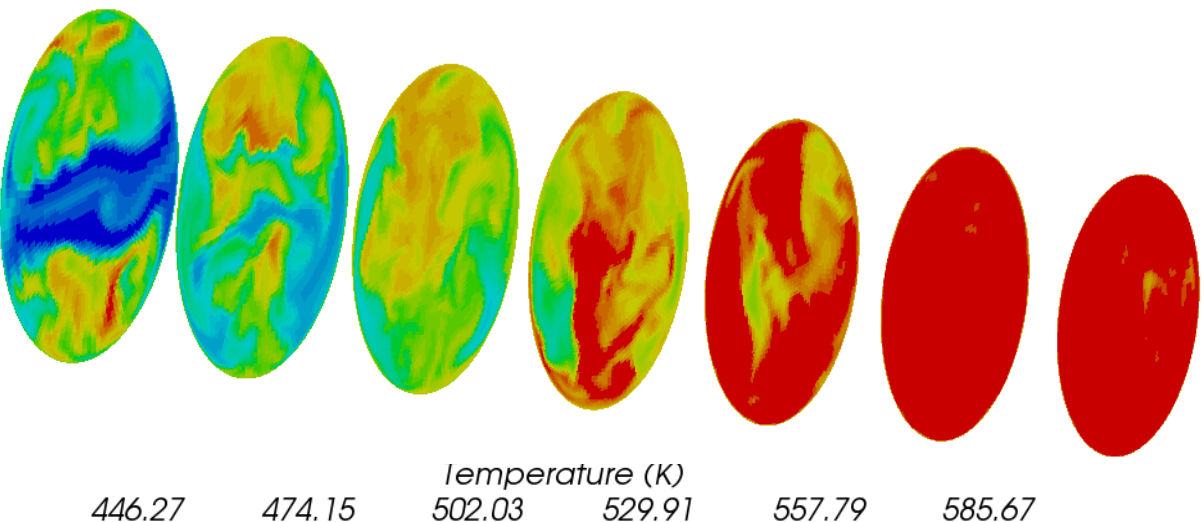

585.67

(Case 38.2b) 


\section{Spalart-Allmaraz Detached Eddy Turbulence Model}

- Temperature

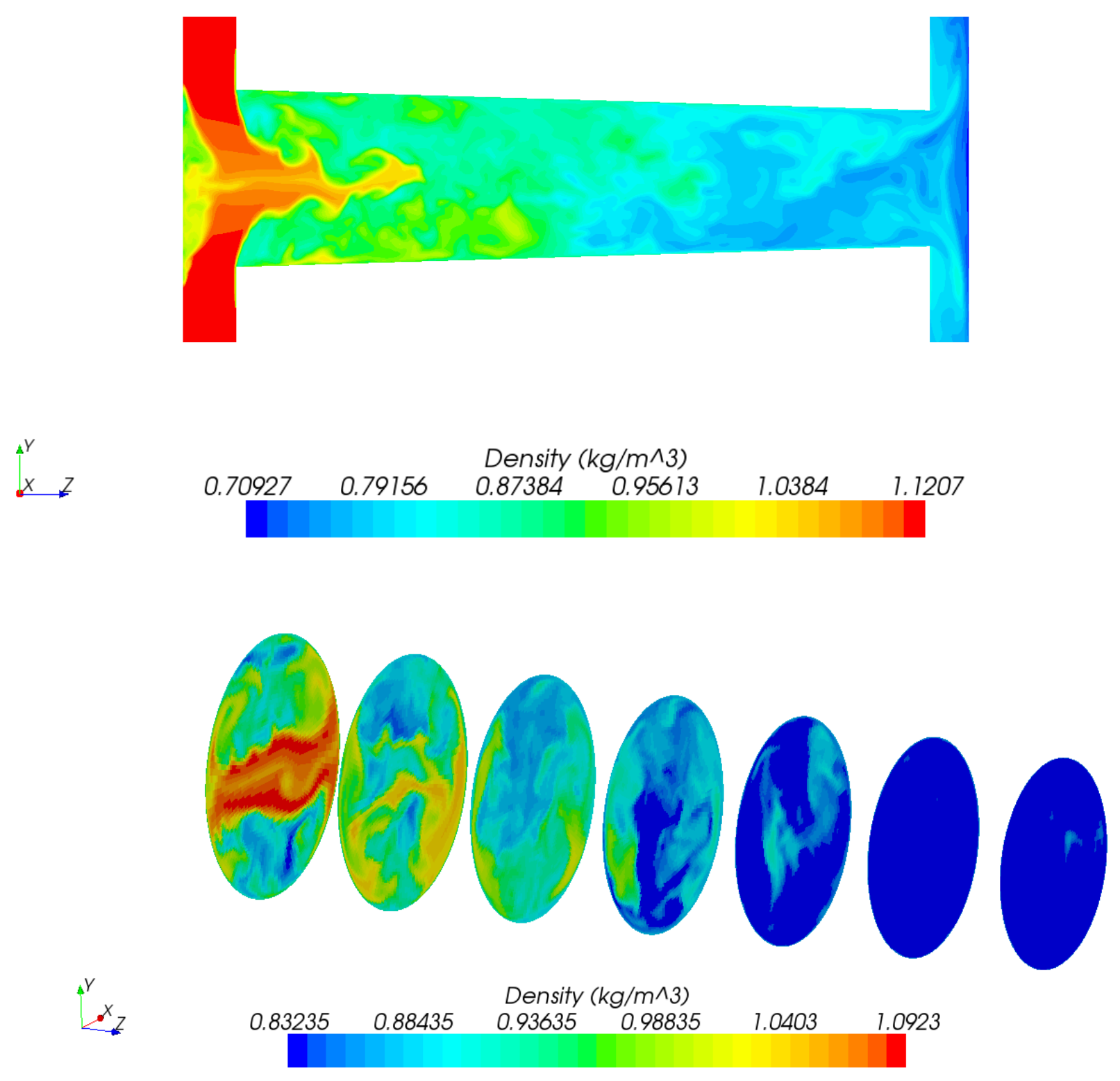

(Case 38.2b) 


\section{Spalart-Allmaraz Detached Eddy Turbulence Model}

- Turbulent Viscosity Ratio

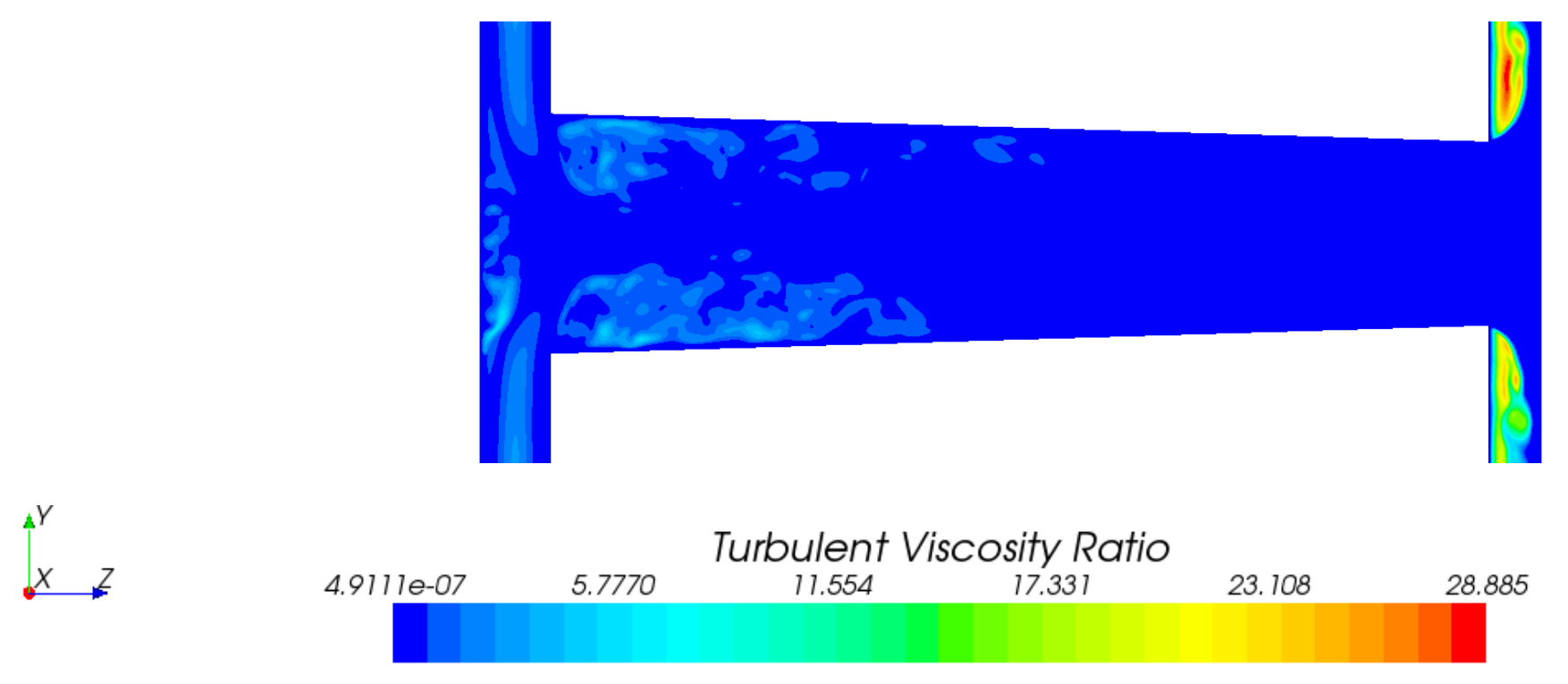

(Case 38.2b) 


\section{Large Eddy Simulation Turbulence Model \\ - Velocity Magnitude}
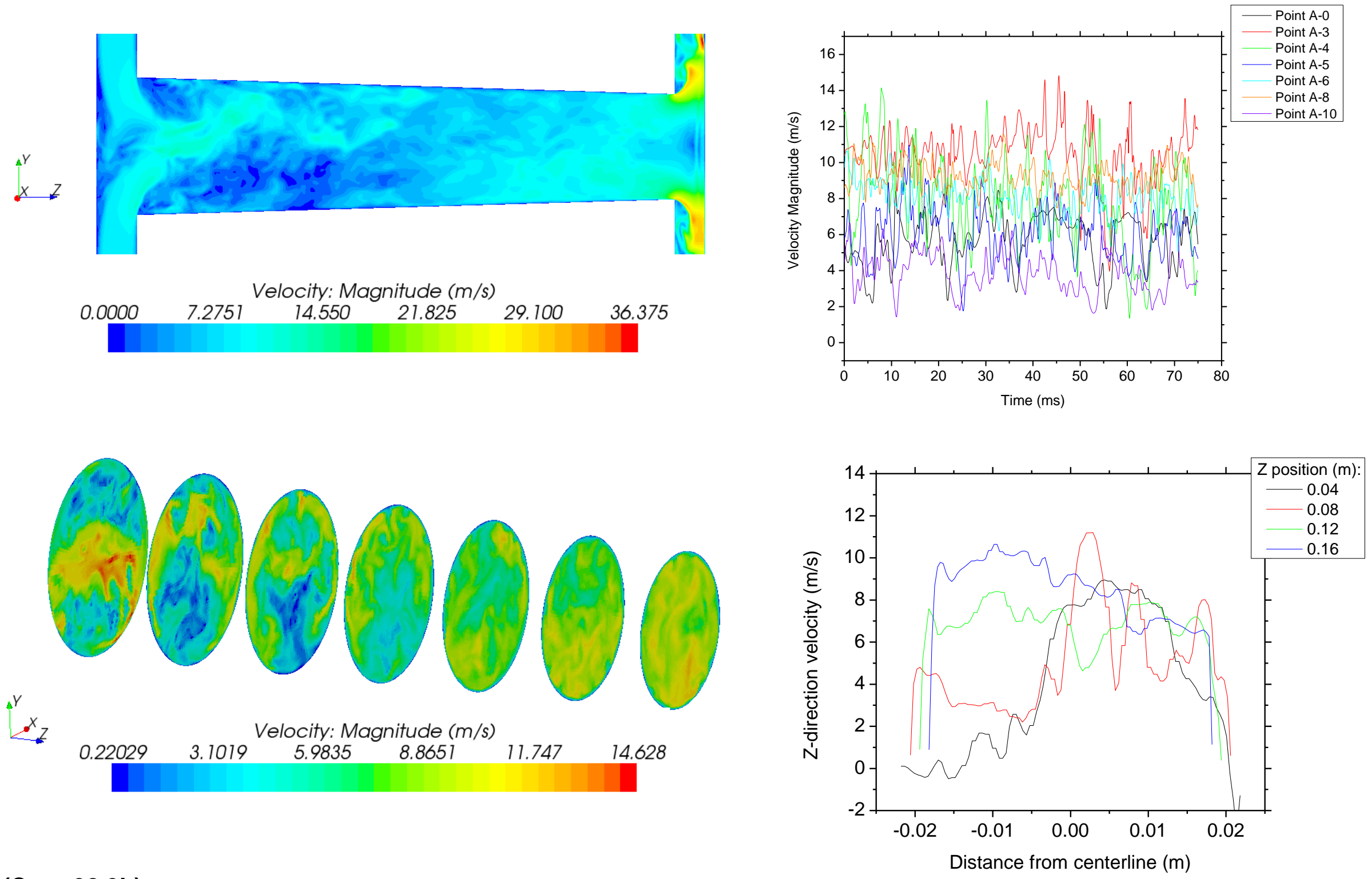

(Case 38.3b) 


\section{Large Eddy Simulation Turbulence Model}

- Temperature
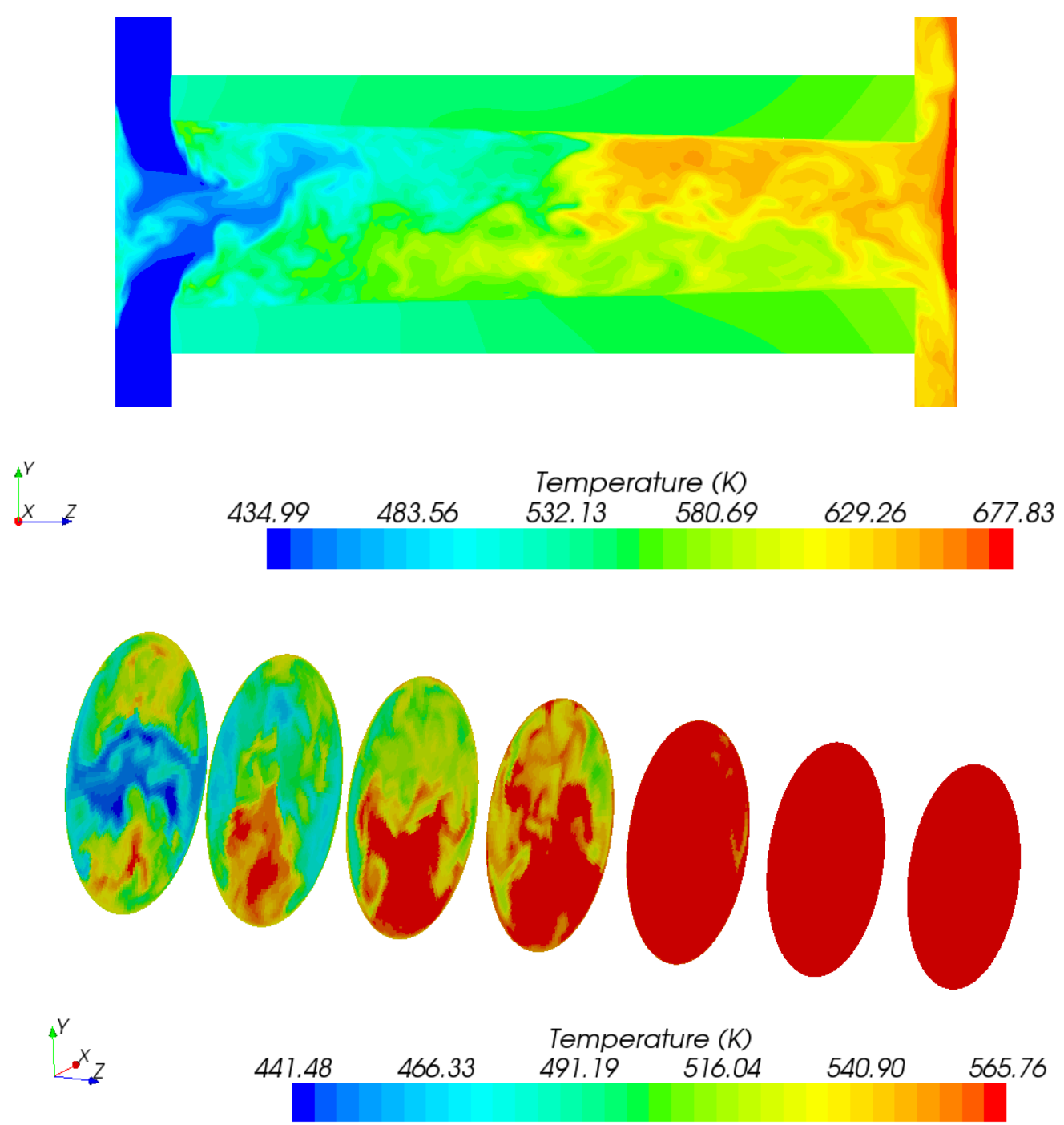

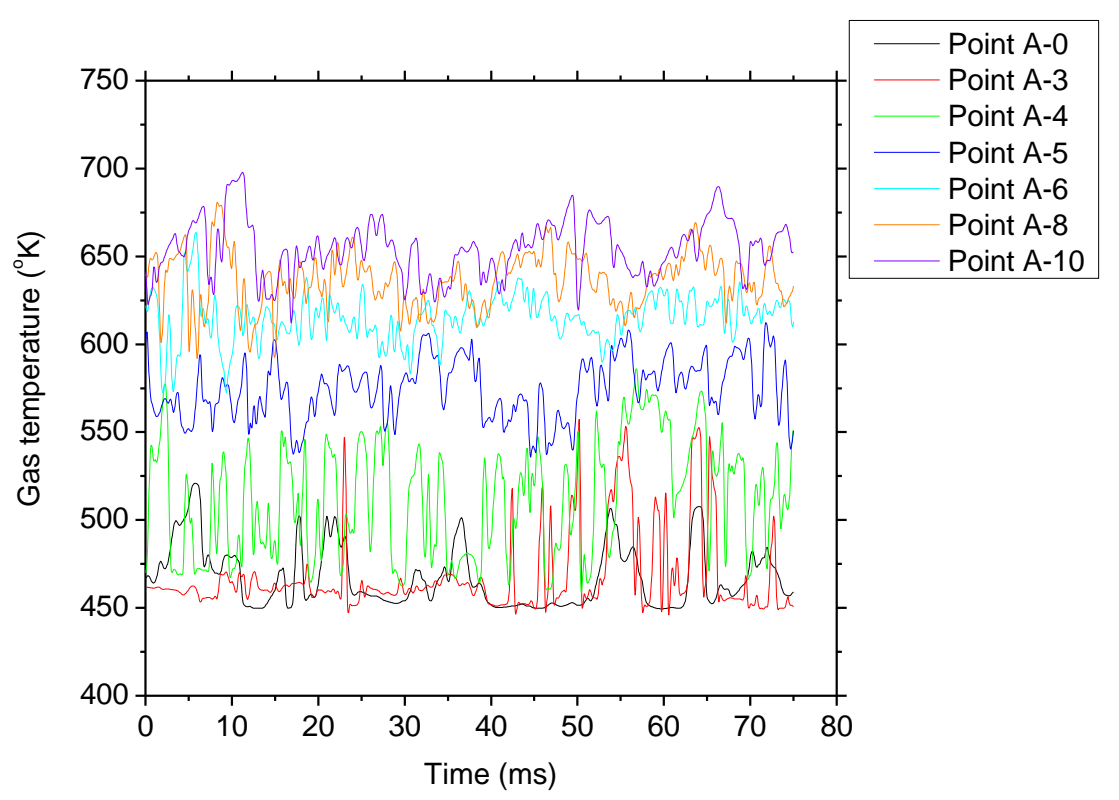

(Case 38.3b) 


\section{Large Eddy Simulation Turbulence Model}

- Density
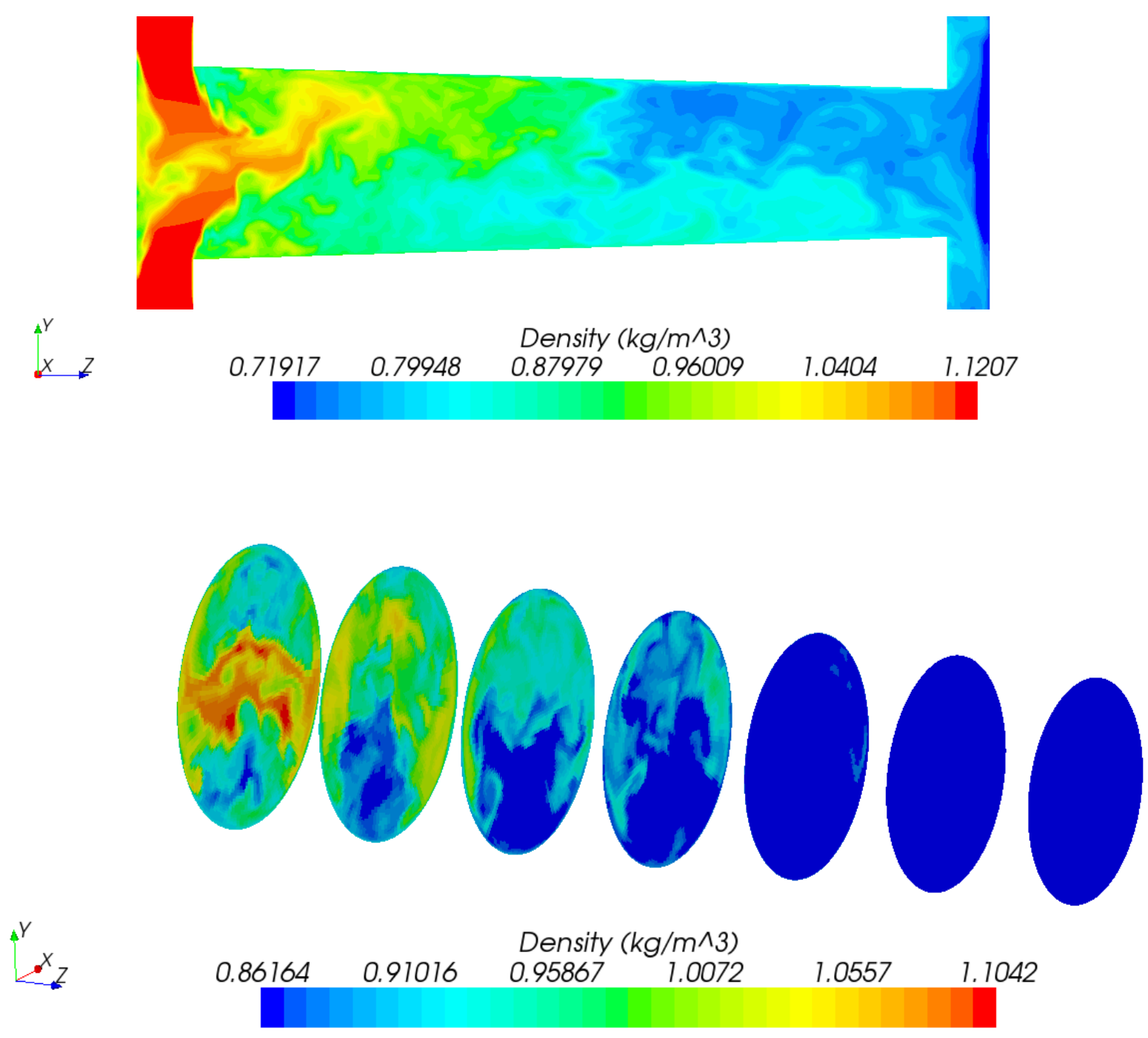

(Case 38.3b) 


\section{Large Eddy Simulation Turbulence Model \\ - Turbulent Viscosity Ratio}

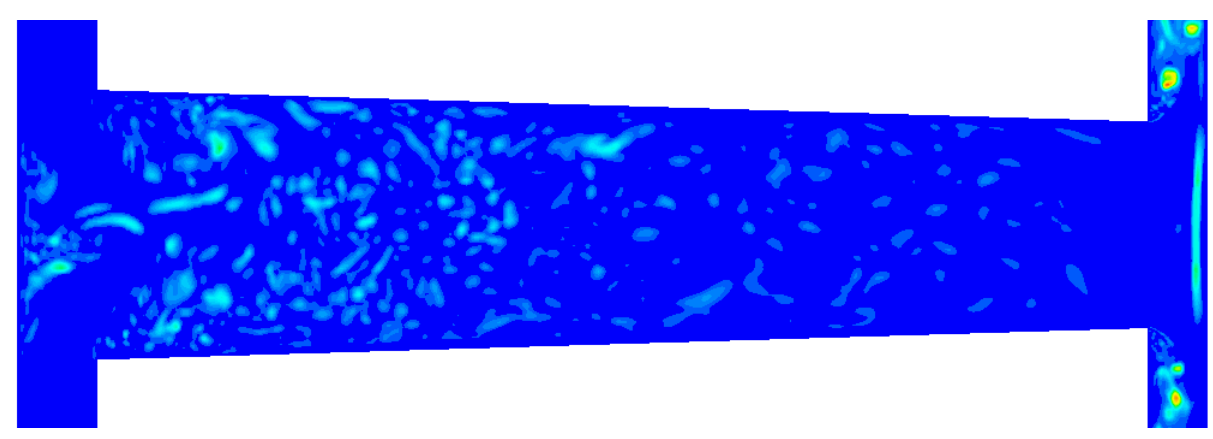

$\int_{X}^{Y} \quad Z$

Turbulent Viscosity Ratio

$1.4492 e-12$

15.657

23.485

31.314

39.142

(Case 38.3b) 


\section{k- $\varepsilon$ Turbulence Model \\ - Velocity Magnitude}
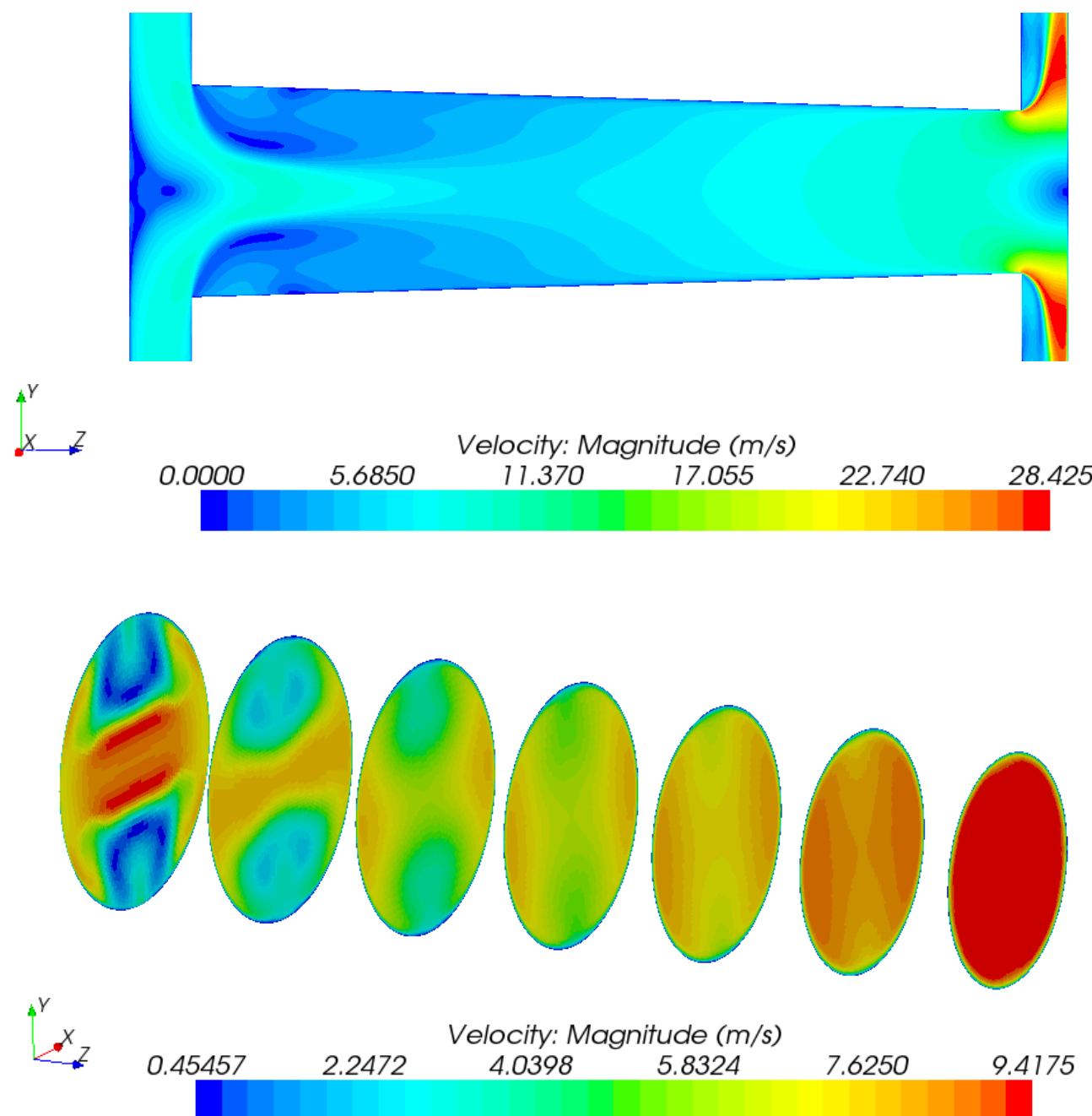

(Case 38.4b)

01/18/11 - LLNL-TR-468217
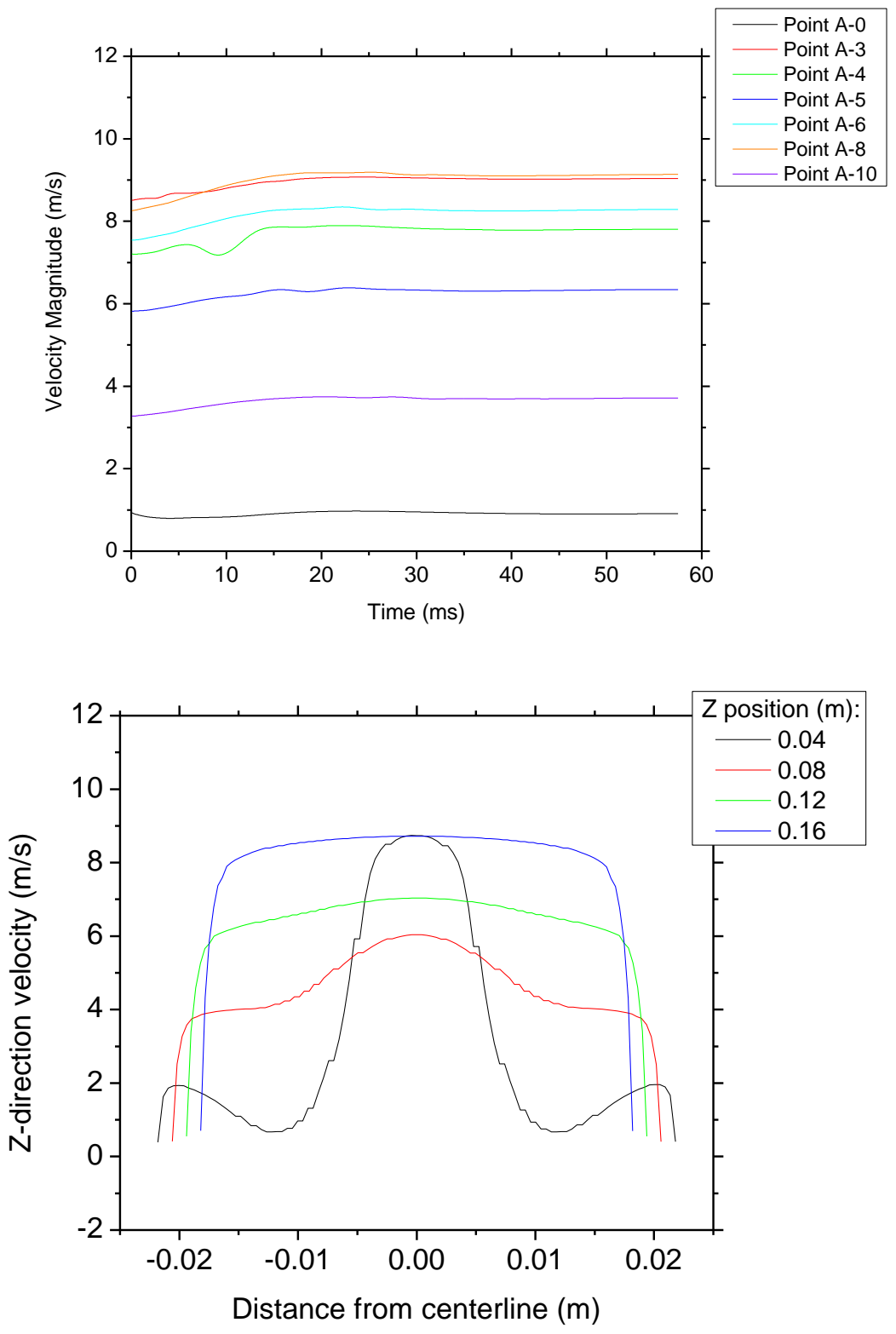


\section{k- $\varepsilon$ Turbulence Model}

- Temperature
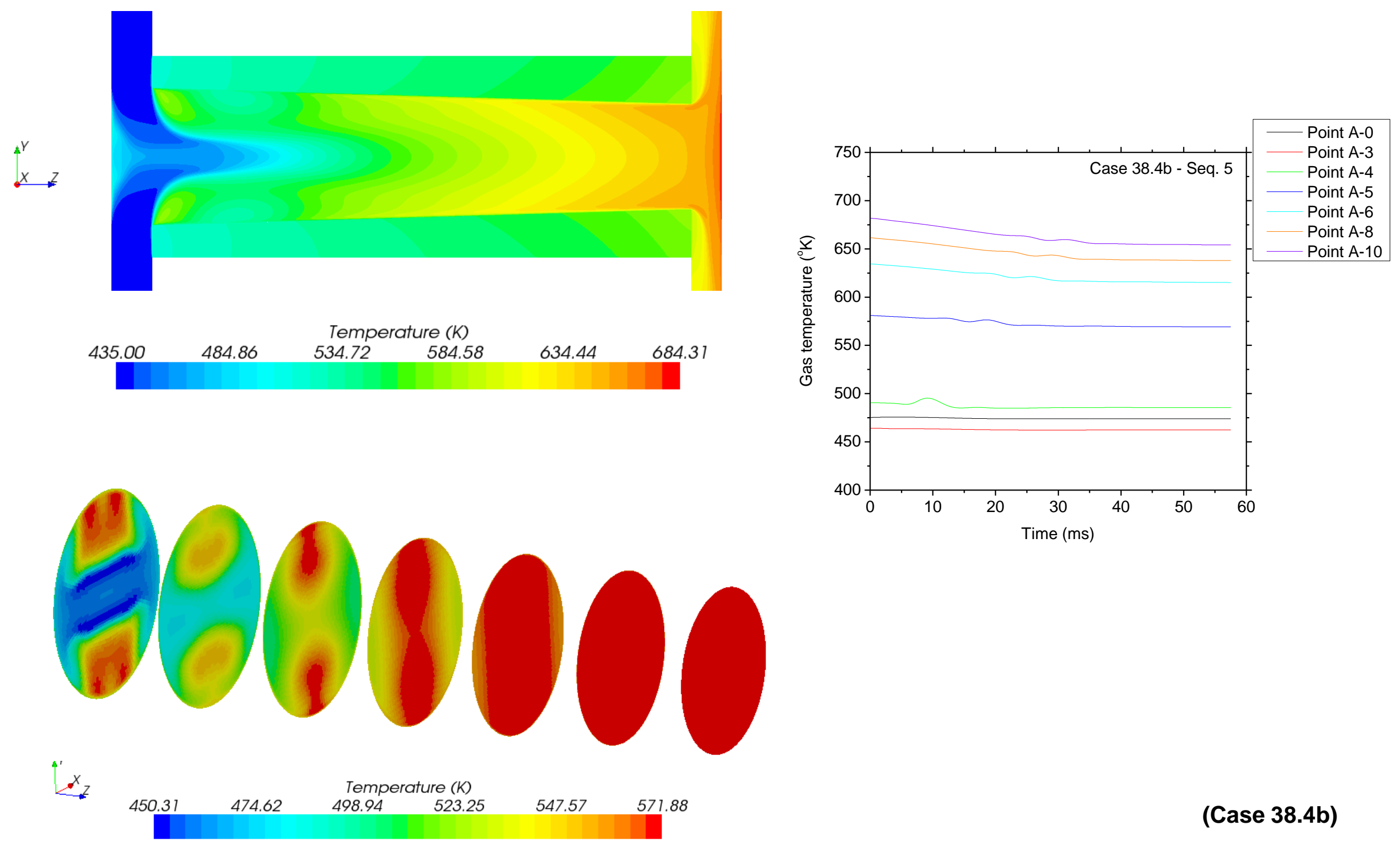

(Case 38.4b) 


\section{k- $\varepsilon$ Turbulence Model \\ - Density}
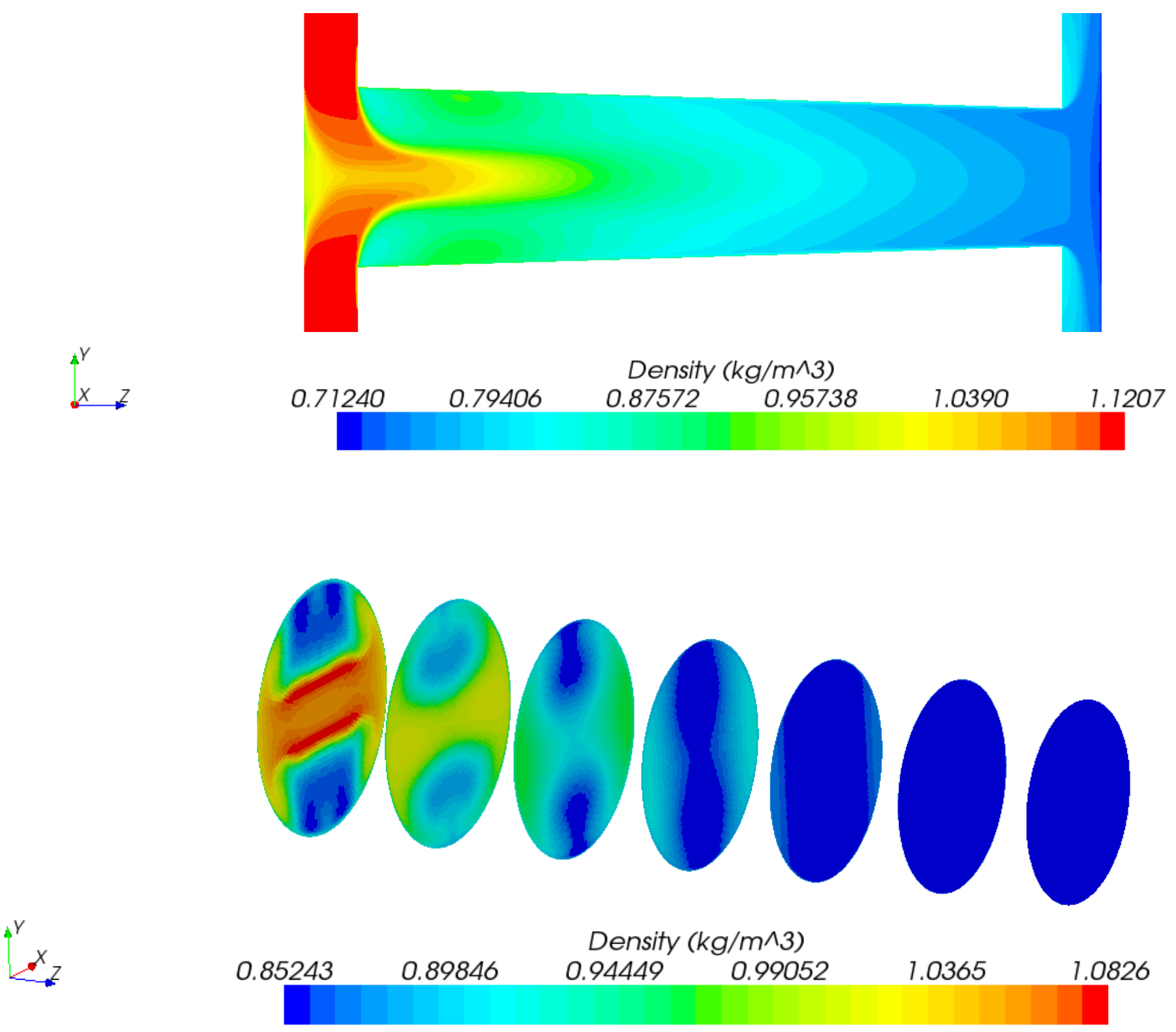

(Case 38.4b) 


\section{k- $\varepsilon$ Turbulence Model}

- Turbulent Viscosity Ratio
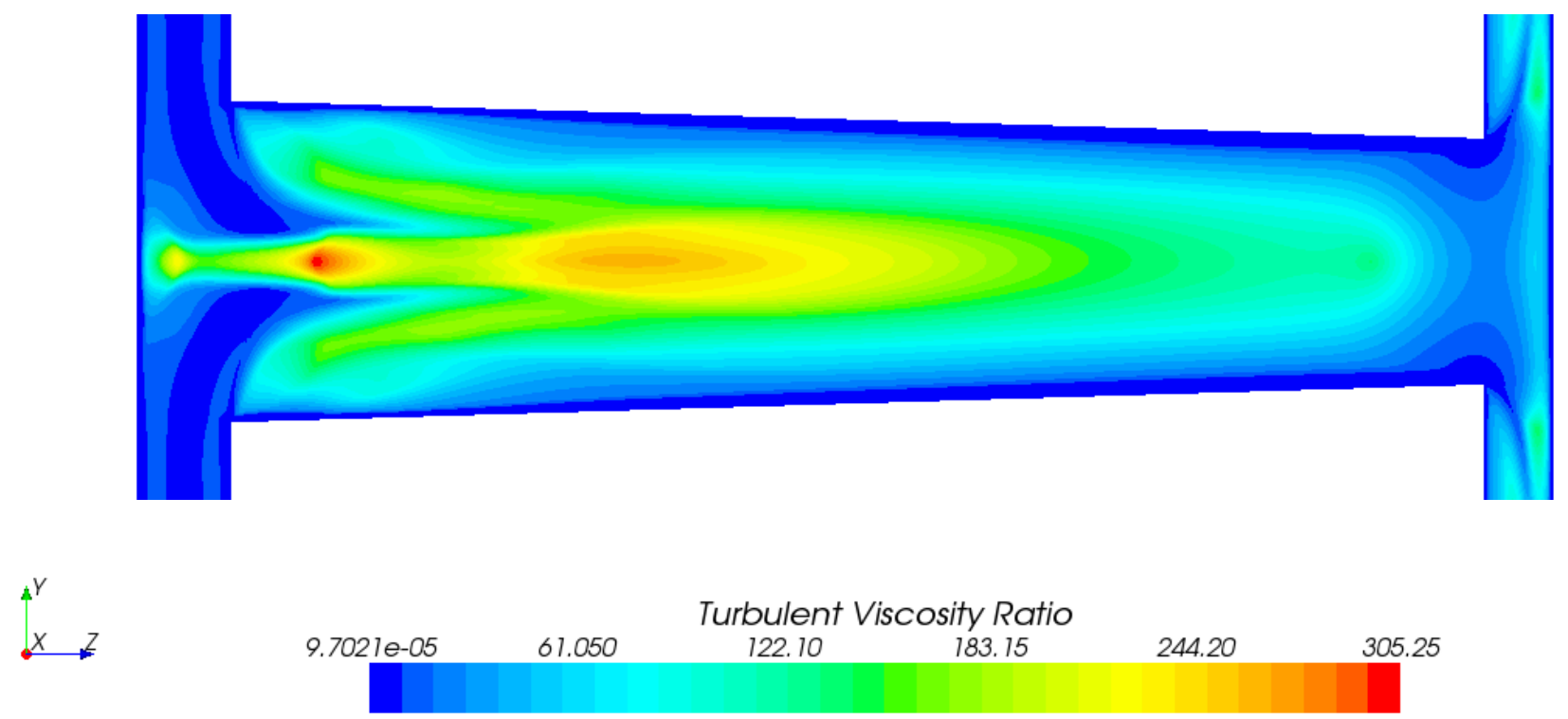

(Case 38.4b) 